\title{
Risk Factors of Neonatal Mortality in Bangladesh
}

\author{
Kamal SMM' ${ }^{1}$, Ashrafuzzaman $\mathbf{M}^{2}$, Nasreen SA $^{3}$
}

'Dr. S. M. Mostafa Kamal, MSc, PhD, Associate Professor, Department of Mathematics, Islamic University, Kushtia, Bangladesh, ${ }^{2} \mathrm{Dr}$. Md. Ashrafuzzaman, MBBS, MPH, Senior Medical Officer, Islamic University, Kushtia, Bangladesh, ${ }^{3}$ Dr. Syeda Anjuman Nasreen, MBBS, M.Phil, Lecturer, Department of Community Medicine, Mymensingh Medical College, Mymensingh, Bangladesh.

Address for correspondence: Dr. Mostafa Kamal, E-mail: kamaliubd@yahoo.com

\begin{abstract}
Introduction: To address United Nations Millennium Development Goal 4 (MDG 4) on reducing childhood mortality rates by two-thirds by 2015 , there is a need for better population-based data on the rates and causes of neonatal death. This study aims to identify the risk factors of neonatal mortality in Bangladesh. Materials and Methods: The study used data from the nationally representative 2007 Bangladesh Demographic and Health Survey. The survey gathered information regarding socioeconomic, demographic, environmental and maternal and child health care of 10,996 ever married women and 6,058 children. Both bivariate and multivariate statistical analyses were used to assess the relationship between neonatal mortality and contextual factors. Results: The prevalence of neonatal mortality was $37 / 1,000$. The statistical analyses yielded quantitatively important and reliable estimates of neonatal death. The multivariate logistic regression analysis yielded significantly increased risk of neonatal mortality for children with mother who had no formal education, the Muslims, whose mother were adolescents of age 15-19, first ranked birth and twin babies. Conclusion: Emphasis should be given to improve female education in Bangladesh for a better chance of satisfying important factors that can improve infant survival: the quality of infant feeding, general care, household sanitation, and adequate use of preventive and curative health services.
\end{abstract}

Key words: Maternal and child health, Female education, MDG 4, Neonatal mortality

\section{Introduction}

$\mathrm{E}^{2}$ ach year nearly four million newborns die during the first 4 weeks of life and world-wide neonatal mortality makes up $40 \%$ of the total child mortality ${ }^{1,2,3,4}$. This means that the overall neonatal mortality rate is about $30 / 1,000$ with an annual number of births in the world reaching 130 million'. Whereas developed countries maintain a neonatal mortality rate of $2-3 / 1,000$, it is not uncommon that this rate reaches over $60 / 1,000$ in the poorer segments of the world 5 . Of the deaths, $99 \%$ are accounting the developing countries, especially in subSaharan African and South Asia ${ }^{1,5,6}$. During the last 30 years, the reduction in neonatal mortality rates has been slower, compared to both under-five and child mortality rates after the first month of life $e^{6,7,8}$.

Millennium Development Goal 4 (MDG 4) calls for reducing the under-five mortality rate by twothirds between 1990 and 2015. As global momentum and investment for accelerating child survival grow, monitoring progress at the global and country levels has become even more critical. The most recent Inter-agency Group for Child Mortality Estimation (IGME) estimates show that nearly 8.1 million under-five children died in 2009 , implies that more than 22,000 children die per day. These figures reflect substantial progress. Globally, the under-five mortality rate has fallen from 89 deaths per 1,000 live births in 1990 to 60 in 2009 . But the rate of decline -a one-third reduction over 20 years -is insufficient to meet MDG 4, particularly in Sub-Saharan Africa, Southern Asia and Oceania. ${ }^{9}$ Neonatal and postneonatal mortality rates declined less ${ }^{10}, 3.0 \%$ and $2.5 \%$ decrease respectively. As a consequence there is an increasing proportion of infant deaths occurring in the neonatal period worldwide, which now accounts for two-thirds of deaths in children less than one year old, and nearly four-tenths of all deaths in children less than five years of age ${ }^{8}$.

Infant and child mortality rates reflect a country's level of socioeconomic development and quality of life. They are used for monitoring and evaluating population 
and health programmes and policies. The rates are also important for monitoring progress towards the United Nations MDG to reduce child mortality as expected by the year 2015. It would be difficult to achieve MDG without reducing child mortality by two-thirds by $2015^{11}$. Thus the study on infant and child mortality; in particular, neonatal mortality is of great importance to monitoring the progress of children's health status.

Bangladesh has made substantial progress in the reduction of under-five mortality. A recent estimate suggests that infant mortality reduced from $88 / 1,000$ in 2000 to 55/1,000 in 2010. Absolutely, in Bangladesh, infant mortality reduced by $3.3 \%$ annually in the last decade. The neonatal and post neonatal mortality reduced from $65 / 1,000$ and $38 / 1,000$ in 1990 to $31 / 1,000$ and 14/1,000 respectively in 2010.5 Besides, the Bangladesh Demographic and Health Surveys (BDHSs) reported that under-five mortality reduced from 133/1,000 in 1993-1994 to 55/1,000 in 2007. In addition, the neonatal and post-neonatal mortality rates declined from $52 / 1,000$ and $35 / 1,000$ to $37 / 1,000$ and $15 / 1,000$ respectively during the same period ${ }^{12,13}$. The successive DHS surveys conducted in Bangladesh since 1993-1994 confirm a declining trend in childhood mortality. During 1989-1993 to 2002-2006, infant mortality declined by $40 \%$ from $87 / 1,000$ live births to $52 / 1,000$. Even more impressive are the $72 \%$ decline in child mortality and the $51 \%$ decline in under-five mortality over the same period. A comparison of mortality rates over the last three years shows that infant and child mortality declined by $20 \%$ and $42 \%$ respectively ${ }^{13}$. A recent study ${ }^{14}$ conducted on rural areas at Matlab using the Health and Demographic Surveillance System (HDSS) data has shown gradual decline in under-five mortality consistent with the reports of the BDHSs.

Whereas literatures on neonatal, post-neonatal, infant and child mortality are enormous in other developed and developing countries, those are limited in Bangladesh. Many studies carried out elsewhere on risk factors of neonatal mortality attempt to show causal relationship between neonatal mortality and utilization of maternal health care facilities, such as receiving antenatal care (ANC) services, place of delivery, skilled attendance during childbirth ${ }^{15,16}$. Caste, religion and standard of living index are also identified as influential factors of childhood mortality in India ${ }^{17}$. A number of studies showed significant relationship between mother's level of education ${ }^{6,16,18}$, maternal age ${ }^{19,20,21,22}$ and early childhood mortality. Mother and child characteristics are analysed as determinants of child mortality and its components, socioeconomic characteristics, type of childbirth and birth defects have been extensively investigated ${ }^{22}$. Regional and social differences may influence the composition of population groups and the success of local health promotion programmes. Living in poor areas may have negative effects on children's health ${ }^{23}$.

Bangladesh is still far away to achieve the MDG 4. To achieve the goal, the infant mortality rate should be reduced at $31 / 1000^{24}$. It would be difficult to achieve MDG of reducing child mortality by two-thirds by 2015 without reducing neonatal mortality. Despite impressive progress, Bangladesh still has higher rate of infant and neonatal mortality. In Bangladesh, very few studies have reported the causes of early and late neonatal deaths ${ }^{16}$. Knowledge on some of the factors affecting child mortality is a fundamental requirement for devising appropriate policies and strategies to accelerate decline in neonatal mortality. This paper aims to investigate the risk factors affecting neonatal mortality in Bangladesh. The findings of this study may help the policy makers, programme managers and donors in driving up understanding about the risk factors of early childhood mortality, particularly neonatal mortality of Bangladeshi children.

\section{Materials and Methods}

Data for this study have been taken from 2007 BDHS. The BDHS is a nationally representative survey of 10,996 women age 15-49 and 3,771 men age 15-54 from 10,400 households and 6,058 under-five children born during the last five years preceding the survey date covering 361 sample points (clusters) throughout Bangladesh, 134 in urban areas and 227 in the rural areas. This survey is the fifth in a series of national-level population and health surveys conducted as part of the global Demographic and Health Surveys (DHS) programme. It was designed to provide data to monitor the population and health situation in Bangladesh as a follow up to the past four BDHS surveys. The survey utilised a multistage cluster sample based on the 2001 Bangladesh Census and was designed to produce separate estimates for key indicators for each of the six divisions of the country Barisal, Chittagong, Dhaka, Khulna, Rajshahi and Sylhet. Data collection took place over a five-month period from 24 March to 11 August, 2007.

The survey obtained detailed information on fertility levels, marriage, fertility preferences, awareness and use of family planning methods, breastfeeding practices, nutritional status of women and young children, childhood mortality, maternal and child health, and knowledge and attitudes regarding HIV/AIDS and other sexually transmitted infections (STIs). The 2007 BDHS was conducted under the authority of the National Institute for Population Research and Training (NIPORT) of the Ministry of Health and Family Welfare. It was implemented by Mitra and Associates, a Bangladeshi 
research firm located in Dhaka. Technical assistance was provided by Macro International Inc. through the MEASURE DHS programme. Financial support for the survey was provided by the U.S. Agency for International Development (USAID/Bangladesh). However, the details of the survey are given elsewhere ${ }^{13}$.

\section{Conceptual Framework}

Many researchers such as Mahmood $^{25}$ and later on Titaley and his colleagues ${ }^{6}$ adapted the conceptual framework proposed by Mosley and Chen ${ }^{26}$ with some modifications based on the limitations and structure of the DHS data. Keeping in view the aforementioned frameworks, this study considered the "survival status" of children as the outcome variable. According to Mosley and Chen ${ }^{26}$ framework, the socioeconomic factors affect the outcome variable through the four proximate determinants namely, socio-demographic factors, environmental factors, nutritional factors and health seeking behaviour of mother. Due to scarcity of information we also used a modified model to investigate the risk factors for neonatal mortality in this study. The BDHS could not gather information of nutritional status of all living and death children such as height, weight or size of children at the time of their birth. Rather, the survey gathered information regarding nutritional status for the living children at the time of survey. Hence, we used mother's body mass index (BMI) as the proxy determinant.

\section{Study Variables}

The primary outcome variable of this study is "neonatal death", which is defined as the death of a live born infant in the first four weeks of life. In the descriptive analyses, the neonatal mortality rate has been expressed as percentage. The outcome variable "neonatal death" was recorded as a binary variable. The explanatory variables included in this study have been defined in Table 1.

\section{Statistical analyses}

Both bivariate and multivariate statistical analyses have been used in this study. Bivariate analyses namely chi-square tests have been applied to examine the association of various independent variables and neonatal mortality. This was followed by multivariate logistic regression analysis. The logistic regression model used in this study is as follows:

$$
P=\frac{1}{1+\mathrm{e}^{-\beta X}}
$$

where, $P$ is the probability of death of a child within the first four weeks of his/her born, $\beta$ is a vector of unknown coefficients and $X$ is the vector of covariates that affect the outcome variable. Thus the general multivariate logistic regression model can be expressed as:

$$
\log _{\mathrm{e}} \frac{P_{i}}{1-P_{i}}=\beta X=\sum \beta_{j} X_{j i}
$$

which expresses the log odds of the outcome variable as a linear function of the independent or explanatory variables. The results of the logistic regression analysis have been presented by regression coefficient ( $\beta$ ), standard error (SE), odds ratios (OR) (exp $\beta)$ with $95 \%$ confidence interval $(\mathrm{Cl})$. The data of this study have been analysed by means of SPSS $v 17$ software.

\section{Results}

\section{Background characteristics of the children}

The characteristics of the study children are presented in Table 2 with the prevalence of neonatal mortality by socioeconomic, demographic, environmental and maternal health care services strata. As shown in the table, slightly over two-fifths were from poor households and a slightly less than two-fifths were from rich households. Four in five children were from rural areas. The more children were from Dhaka division, followed by Chittagong, Rajshahi, Khulna, Sylhet and Barisal divisions respectively. With regards to mother's education, slightly over one-fourth had no formal education and over two-fifths had at least secondary level of education. The vast majorities were Muslims. $29 \%$ of the mothers were adolescents during childbirth, almost one-third were aged 20-24, one-fifth were aged 25-29 and the rests were of age 30-49. One-third of the children were the first ranked children, one-fifth were the second ranked children and the rest were third or higher ranked children. Half of the children were male and half were female. Almost $99 \%$ of the children were singleton birth and slightly over $1 \%$ was twin or multiple in terms of foetus type. Approximately one-third of the mothers were thin, three in five were normal and $8 \%$ were overweight or obese. One-fourth of the children used to defecate in the unhygienic places, only $8 \%$ children were from households with less polluted cooking fuel and only $3 \%$ had no facilities of safe drinking water. Over half of the mothers received ANC services, whereas less than one-fourth sought skilled birth assistance (SBA) and only $15 \%$ births were delivered in medical facility places.

\section{Prevalence of neonatal mortality}

The third broad column of Table 2 shows the percentage of neonatal mortality by various characteristics under socioeconomic, demographic, environmental and maternal health care factors. Primarily sixteen variables were included in the analyses to examine their association with neonatal mortality. Overall, the neonatal mortality was 37/1000. Of the variables included in the study wealth index, region, 
sex of child, mother's BMI, drinking water facility and maternal health care factors did not show to have significant association with neonatal mortality. The variables identified to have significant association with neonatal mortality were place of residence, maternal education, religion, maternal age, type of foetus, toilet facility and cooking fuel.

As expected, the prevalence of neonatal mortality was $1.1 \%$ higher in rural than urban areas (urban $2.8 \%$ vs. rural 3.9\%). Although, the administrative regions did not show significant association with neonatal mortality, the prevalence varied 30/1,000 in Khulna division to 52/1,000 in Sylhet division. Maternal education and maternal age showed negative association with neonatal mortality. The Muslims had higher rate of neonatal mortality than their peer non-Muslims. The prevalence of neonatal mortality was higher for the first and fifth or higher ranked births than that of the the second, third or fourth. The prevalence of neonatal mortality among twin or multiple births was $325 / 1,000$ as against of 33/1,000 for singleton birth. Households with unhygienic toilet facility and polluted cooking fuel showed higher prevalence of neonatal mortality than those with hygienic toilet facility and less polluted cooking fuel.

\section{Results of multivariate logistic regression analysis}

The results of the multivariate logistic regression analysis have been shown in Table 3 . All the variables identified to have significant association with neonatal mortality were included in the multivariate analysis to assess their net effect. After controlling for other confounding factors, the environmental factors and maternal health care services appeared to have no significant effect on neonatal mortality. The variables showed to have net effect on neonatal mortality were maternal education, religion, maternal age, birth order and type of foetus.

Maternal education showed negative relationship with neonatal mortality. For instance, the odds of neonatal death was significantly $28 \%, 33 \%$ and $85 \%$ lower among children whose mother had primary, secondary and higher education than those who had mothers with no formal education. The non-Muslim children had $40 \%$ lower risk of neonatal death as compared to the Muslim children. Maternal age showed negative relationship with neonatal mortality of the children. As compared to first ranked birth, the second ranked birth had significantly $50 \%$ lower risk of neonatal death, whereas the difference of likelihood of neonatal death between third and higher ranked births and the first ranked had no significant effect. The twin or multiple births were at 15.2 times as likely as to be dying at neonatal period than that of the singleton birth.

Table 1: Operational definition and categorization of the variables used in the analysis

\begin{tabular}{|c|c|}
\hline Variables & Definition and Categorization \\
\hline \multicolumn{2}{|c|}{ Socioeconomic factors } \\
\hline Wealth index & $\begin{array}{l}\text { Household wealth index: } \\
\text { (1) Poorest; (2) Poorer; (3) Medium; (4) Richer; and (5) Richest. }\end{array}$ \\
\hline Residence & $\begin{array}{l}\text { Place of residence: } \\
\text { (1) Urban; and (2) Rural. }\end{array}$ \\
\hline Region & $\begin{array}{l}\text { Administrative regions: } \\
\text { (1) Barisal; (2) Chittagong; (3) Dhaka; (4) Khulna; (5) Rajshahi; } \\
\text { and (6) Sylhet. }\end{array}$ \\
\hline Maternal education & $\begin{array}{l}\text { Mother's level of education: } \\
\text { (1) No education; (2) Primary; (3) Secondary; and (4) Higher. }\end{array}$ \\
\hline Religion & $\begin{array}{l}\text { Religion of mother: } \\
\text { (1) Islam; and (2) Others. }\end{array}$ \\
\hline \multicolumn{2}{|l|}{ Demographic factors } \\
\hline Maternal age & $\begin{array}{l}\text { Mother's age at child birth: } \\
\text { (1) } 15-19 ; \text {; (2) } 20-24 \text {; (3) } 25-29 ; \text { (4) } 30-34 ; \text { (5) 35-49. }\end{array}$ \\
\hline Birth order & $\begin{array}{l}\text { Birth rank of child: } \\
\text { (1) First; (2) Second; (3) Third; (4) Fourth; and (5) Fifth or above }\end{array}$ \\
\hline Sex of child & $\begin{array}{l}\text { Sex of child: } \\
\text { (1) Male; and (2) Female. }\end{array}$ \\
\hline Number of foetus & $\begin{array}{l}\text { Whether child is twin: } \\
\text { (1) Single; and (2) Twin. }\end{array}$ \\
\hline Mother's BMI & $\begin{array}{l}\text { Mother's body mass index: } \\
\text { (1)Thin }(\mathrm{BMI}<18.5) \text {; (2) Normal }(\mathrm{BMI}=18.5-24.5) \text {; and } \\
\text { Over weight/Obese }(\mathrm{BMI}>24.5) \text {. }\end{array}$ \\
\hline
\end{tabular}


Table 1 continued...

\begin{tabular}{|l|l|}
\hline Variables & Definition and Categorization \\
\hline Environmental factors & $\begin{array}{l}\text { Sources of drinking water: } \\
\text { (1) Safe water (Piped, tube well bottle); and (2) Unsafe water (Well, pond, others) }\end{array}$ \\
\hline Drinking water & $\begin{array}{l}\text { Type of toilet facilities: } \\
\text { (1) Hygienic (Flush, pit latrine); and (2) unhygienic (Open field, jungle etc.) }\end{array}$ \\
\hline Toilet facility & $\begin{array}{l}\text { Type of cooking fuel: } \\
\text { (1) Less polluted (Gas, Kerosin); and polluted (Dried cow dung, leaves, wood etc.) }\end{array}$ \\
\hline Cooking fuel & $\begin{array}{l}\text { Sought antenatal care services during pregnancy: } \\
\text { (1) No; and (2) Yes. }\end{array}$ \\
\hline Maternal health care behavioural factors \\
\hline SBA seeking & $\begin{array}{l}\text { Sought skilled birth assistance during child delivery: } \\
\text { (1) No; and (2) Yes. }\end{array}$ \\
\hline Place of delivery & $\begin{array}{l}\text { Medically facilitated place of child delivery: } \\
\text { (1) No; and (2) Yes. }\end{array}$ \\
\hline
\end{tabular}

Table 2: Background characteristics of under-five children and prevalence of neonatal death, BDHS-2007

\begin{tabular}{|c|c|c|c|c|c|}
\hline \multirow{2}{*}{ Background Characteristics } & \multicolumn{2}{|c|}{ No. of Children } & \multicolumn{2}{|c|}{$\%$ of Neonatal Death } & \multirow{2}{*}{ Chi-square } \\
\hline & $\mathbf{N}$ & $\%$ & No & Yes & \\
\hline Wealth Index & & & & & 5.07 \\
\hline Poorest & 1367 & 22.6 & 95.8 & 4.2 & \\
\hline Poorer & 1312 & 21.7 & 96.3 & 3.7 & \\
\hline Middle & 1173 & 19.4 & 95.9 & 4.1 & \\
\hline Richer & 1149 & 19.0 & 96.5 & 3.5 & \\
\hline Richest & 1056 & 17.4 & 97.3 & 2.7 & \\
\hline Place of Residence & & & & & $2.94^{\dagger}$ \\
\hline Urban & 1249 & 20.6 & 97.2 & 2.8 & \\
\hline \begin{tabular}{l|l} 
& Rural \\
\end{tabular} & 4809 & 79.4 & 96.1 & 3.9 & \\
\hline Region & & & & & 5.87 \\
\hline Barisal & 383 & 6.3 & 96.6 & 3.4 & \\
\hline Chittagong & 1337 & 22.1 & 96.5 & 3.5 & \\
\hline Dhaka & 1908 & 31.5 & 96.7 & 3.3 & \\
\hline Khulna & 578 & 9.5 & 97.0 & 3.0 & \\
\hline Rajshahi & 1306 & 21.6 & 95.8 & 4.2 & \\
\hline \begin{tabular}{l|l} 
Sylhet \\
\end{tabular} & 547 & 9.0 & 94.8 & 5.2 & \\
\hline Maternal Education & & & & & $11.26^{* *}$ \\
\hline No education & 1658 & 27.4 & 95.6 & 4.4 & \\
\hline Primary & 1910 & 31.5 & 96.3 & 3.7 & \\
\hline Secondary & 2122 & 35.0 & 96.4 & 3.6 & \\
\hline Higher & 366 & 6.0 & 99.3 & 0.7 & \\
\hline Religion & & & & & $3.35^{*}$ \\
\hline \begin{tabular}{l|l} 
Islam \\
\end{tabular} & 5558 & 91.8 & 96.2 & 3.8 & \\
\hline Other & 499 & 8.2 & 97.8 & 2.2 & \\
\hline Maternal Age & & & & & $16.65^{* * *}$ \\
\hline $15-19$ & 1769 & 29.2 & 94.8 & 5.2 & \\
\hline $20-24$ & 1977 & 32.6 & 96.6 & 3.4 & \\
\hline $25-29$ & 1254 & 20.7 & 97.2 & 2.8 & \\
\hline $30-34$ & 714 & 11.8 & 96.9 & 3.1 & \\
\hline $35-49$ & 343 & 5.7 & 98.1 & 1.9 & \\
\hline
\end{tabular}


Table 2 continued ...

\begin{tabular}{|c|c|c|c|c|c|}
\hline \multirow{2}{*}{ Background Characteristics } & \multicolumn{2}{|c|}{ No. of Children } & \multicolumn{2}{|c|}{$\%$ of Neonatal Death } & \multirow{2}{*}{ Chi-square } \\
\hline & $\mathbf{N}$ & $\%$ & No & Yes & \\
\hline Birth Order & & & & & $16.12^{* *}$ \\
\hline First & 2050 & 33.8 & 95.2 & 4.8 & \\
\hline Second & 1568 & 25.9 & 97.7 & 2.3 & \\
\hline Third & 1009 & 16.7 & 96.5 & 3.5 & \\
\hline Fourth & 648 & 10.7 & 96.6 & 3.4 & \\
\hline Fifth+ & 782 & 12.9 & 95.9 & 4.1 & \\
\hline Sex of Child & & & & & 0.62 \\
\hline Male & 3021 & 49.9 & 96.1 & 3.9 & \\
\hline Female & 3036 & 50.1 & 96.5 & 3.5 & \\
\hline Number of Foetus & & & & & $197.50^{* * *}$ \\
\hline Single & 5975 & 98.6 & 96.7 & 3.3 & \\
\hline Twin & 83 & 1.4 & 67.5 & 32.5 & \\
\hline Mother's BMI & & & & & 1.75 \\
\hline \begin{tabular}{l|l} 
Thin $(\mathrm{BMI}<18.5)$ \\
\end{tabular} & 1935 & 32.3 & 96.1 & 3.9 & \\
\hline Normal (BMI 18.5-24.9) & 3593 & 60.0 & 96.4 & 3.6 & \\
\hline Over weight $(\mathrm{BMI}=>25.0)$ & 462 & 7.7 & 97.5 & 2.5 & \\
\hline Drinking Water ${ }^{\S}$ & & & & & 0.01 \\
\hline \begin{tabular}{l|l} 
Safe \\
\end{tabular} & 5251 & 96.6 & 96.2 & 3.8 & \\
\hline Unsafe & 185 & 3.4 & 96.3 & 3.7 & \\
\hline Toilet Facility ${ }^{\S}$ & & & & & $4.08^{*}$ \\
\hline Hygienic & 4309 & 79.3 & 96.5 & 3.5 & \\
\hline Unhygienic & 1127 & 20.7 & 95.2 & 4.8 & \\
\hline Cooking fuel ${ }^{\S}$ & & & & & $4.97^{*}$ \\
\hline Less polluted & 436 & 8.0 & 98.2 & 1.8 & \\
\hline Polluted & 5000 & 92.0 & 96.0 & 4.0 & \\
\hline Sought ANC services ${ }^{\ddagger}$ & & & & & 1.97 \\
\hline No & 2365 & 48.3 & 97.9 & 2.1 & \\
\hline \begin{tabular}{l|l} 
Yes \\
\end{tabular} & 2535 & 51.7 & 98.5 & 1.5 & \\
\hline Sought SBA ${ }^{\ddagger}$ & & & & & 0.38 \\
\hline \begin{tabular}{l|l} 
No \\
\end{tabular} & 4957 & 81.9 & 96.2 & 3.8 & \\
\hline \begin{tabular}{|l|} 
Yes \\
\end{tabular} & 1093 & 18.1 & 96.6 & 3.4 & \\
\hline Delivery setting $^{\neq}$ & & & & & 0.13 \\
\hline Home & 5164 & 85.3 & 96.3 & 3.7 & \\
\hline Hospital & 887 & 14.7 & 96.5 & 3.5 & \\
\hline Total & 6058 & 100.0 & 96.3 & 3.7 & \\
\hline
\end{tabular}

Note: level of significance ${ }^{* * *} p<0.001 ;{ }^{* *} p<0.01 ;{ }^{*} p<0.05$; and ${ }^{\dagger} p<0.10$.

$\S$ The figures do not round to 6,058 due to exclusion of non-dejure residents.

${ }^{\ddagger}$ The figures do not round to various missing information.

Table 3: Multivariate logistic regression analysis showing the risk of neonatal mortality among under-five children of Bangladesh, BDHS-2007

\begin{tabular}{|c|c|c|c|c|}
\hline Background Characteristics & $\beta$ & SE & OR & $95 \% \mathrm{Cl}$ \\
\hline \multicolumn{5}{|l|}{ Maternal Education } \\
\hline \begin{tabular}{l|l} 
No education \\
\end{tabular} & Reference & --- & --- & --- \\
\hline Primary & -0.33 & 0.18 & $0.72^{*}$ & $0.50-1.03$ \\
\hline Secondary & -0.41 & 0.19 & $0.67^{*}$ & $0.46-0.97$ \\
\hline Higher & -1.93 & 0.65 & $0.15^{* *}$ & $0.04-0.52$ \\
\hline \multicolumn{5}{|l|}{ Religion } \\
\hline Islam & Reference & --- & --- & --- \\
\hline Other & -0.51 & 0.32 & $0.60^{+}$ & $0.32-1.12$ \\
\hline
\end{tabular}


Table 3 continued ...

\begin{tabular}{|c|c|c|c|c|}
\hline \multicolumn{5}{|c|}{ Maternal Age } \\
\hline \begin{tabular}{l|l}
$15-19$ \\
\end{tabular} & Reference & -- & --- & --- \\
\hline $20-24$ & -0.35 & 0.20 & $0.70^{*}$ & $0.48-1.03$ \\
\hline $25-29$ & -0.62 & 0.28 & $0.54^{*}$ & $0.31-0.93$ \\
\hline $30-34$ & -0.80 & 0.35 & $0.45^{* *}$ & $0.23-0.89$ \\
\hline $35-49$ & -1.40 & 0.50 & $0.25^{* *}$ & $0.09-0.66$ \\
\hline \multicolumn{5}{|l|}{ Birth Order } \\
\hline \begin{tabular}{l|l} 
& First \\
\end{tabular} & Reference & -- & --- & --- \\
\hline Second & -0.70 & 0.22 & $0.50^{* * * *}$ & $0.32-0.76$ \\
\hline Third & -0.25 & 0.26 & 0.78 & 0.47-1.29 \\
\hline Fourth & -0.28 & 0.33 & 0.75 & $0.40-1.42$ \\
\hline Fifth+ & 0.14 & 0.35 & 1.14 & $0.58-2.26$ \\
\hline \multicolumn{5}{|c|}{ Number of Foetus } \\
\hline \begin{tabular}{l|l} 
Single \\
\end{tabular} & Reference & -- & --- & --- \\
\hline Twin & 2.72 & 0.26 & $15.20^{* * *}$ & $9.16-25.22$ \\
\hline
\end{tabular}

Note: level of significance ${ }^{* * *} p<0.001 ;{ }^{* *} p<0.01 ;{ }^{*} p<0.05$; and ${ }^{\dagger} p<0.10$.

\section{Discussion}

To address United Nationas MDG 4 on reducing childhood mortality, there is a need for better populationbased data on the rates and causes of neonatal death ${ }^{27}$. In this study it was our aim to identify the risk factors of neonatal death in Bangladesh using the nationally representative 2007 BDHS data. Both bivariate and multivariate statistical analyses were employed to examine the factors affecting neonatal death. Findings showed that the prevalence of overall neonatal death was 37/1,000. Our analyses revealed that socioeconomic and demographic factors rather than environmental factors and maternal health care services had significant net effect on neonatal death. The variables influencing neonatal death are maternal education, religion, maternal age, birth order and type of foetus.

Consistent with earlier studies ${ }^{18,28,29,30}$, the findings of this study revealed that the higher the mother's education the lower the risk of neonatal mortality. A review of the literature shows that while the higher socioeconomic status of better educated women explains about half of the magnitude of the relationship between maternal education and child survival ${ }^{31}$, the domestic health practice of individual women is probably the new most salient mechanism in the maternal education child mortality relationship. The fact that mother's education is a more important determinant of child survival than father's education: explains that there is greater maternal involvement in child-health related care ${ }^{32}$. The mother's education influences her choices and skills in health care practices ${ }^{32,33}$. For instance, both educated and illiterate mothers recognize when their child is sick but an educated mother more frequently will take action "without waiting for (her) husband or mother-in-law to notice the child's condition too" ${ }^{32}$. This is partly because illiterate women do feel a lack of capability when dealing with the modern world.

We found that being born to a mother who practiced Islam was significantly associated with an increased risk of neonatal death. The influence of religion on neonatal mortality may be linked to the beliefs and myths they may have concerning child birth. This was the case with the Faith Assembly people in Indiana, U.S., who believed that child bearing was an act of God not to be interfered with ${ }^{34}$. It is evident that Muslim women have higher fertility, lower use rate of contraceptive method, early age at marriage and motherhood and lower access to maternal health care services than their peer non-Muslim sisters in Bangladesh ${ }^{35,36}$. Hence, we explored this association further by introducing an interaction term between religion and maternal age (results not shown). We found that children who were born to Muslim adolescent mothers had a higher risk of neonatal deaths compared to children born to nonMuslim mothers (results not shown). Despite this, it is difficult to say whether or not this finding reflects the early motherhood among the subgroup of traditional Muslim women and thus further qualitative research may be useful.

Our findings showed significant increased risk between adolescent motherhood and neonatal mortality. This result is comparable to numerous studies conducted elsewhere which found higher risk of neonatal mortality in younger adolescents than older mothers ${ }^{19,20,22}$. This is partially explained by differences in socioeconomic factors in younger versus older women and is mediated primarily through preterm delivery, small for gestational age (SGA) and low birth weight (LBW) or some interaction of these variables ${ }^{37}$. The significance of young and old maternal ages at childbirth 
as risk factors for adverse neonatal health outcomes remains largely socioeconomic, environmental and cultural context dependent. Previous research that aimed at providing an explanation to the frequently observed association between mother's age and various quality-of-life measures, including perinatal, neonatal and infant mortality ${ }^{38,39}$, preterm delivery ${ }^{38,40}$, and low birth weight ${ }^{41,42}$ have yielded inconsistent results.

Birth order of a child showed controversial results for neonatal mortality. Some studies showed that first or lower ranked births were at higher risk of neonatal mortality, whereas some others showed that higher ranked births were at increased risk of neonatal mortality. For instance, in a study to determine the impact of maternal and child health $(\mathrm{MCH})$ services on child survival in a socio-economically poor rural Pondicherry, India, infants of first birth had higher risk of neonatal mortality than fourth or higher ranked births. The study further showed that second ranked births had the least mortality risk ${ }^{42}$. A study conducted in Taiwan ${ }^{44}$ showed that children with first and fifth ranked births were at higher risk of early neonatal deaths, while in Nigeria ${ }^{45}$, the children with sixth or higher order births were at increased risk of neonatal mortality. It is argued that, in most of the developing countries, higher mortality risks were found for the first-born children compared to birth order two through six ${ }^{46}$. Our study showed that children with first ranked birth were significantly at increased risk of dying at early infancy than the second or higher ranked births. Social and cultural contexts may be partly attributed to the influence on birth order on neonatal mortality. However, our studies are consistent with most of the earlier studies as mentioned above.

Multiple births are relatively rare events, but contribute substantially to mortality in both neonatal and post-neonatal periods ${ }^{28}$. Our study showed a reduced risk of neonatal mortality for singleton baby compared to twins or multiples. Twins are more likely to be born with low birth weight and biological immaturity. Possibly, the use of the curative services, which are needed in emergency situations, could be underutilized by mothers of twins ${ }^{47}$. However, one possible reason for this observed association is that multi-foetal pregnancy and multiple births including twins and higher order multiples such as triplets and quadruplets are high-risk pregnancy and birth. These high-risk births are frequently accompanied by a number of associated foetal and neonatal complications that require special and expensive medical $\mathrm{care}^{48}$. In addition, multiplebirth children are at greater risk of birth defects and/ or disabilities and accounted for larger percentage of prenatal deaths ${ }^{49}$. Therefore, mortality of these highrisk groups contributes to the higher rate of childhood mortality especially during the early period of life. This finding is consistent with earlier studies conducted elsewhere $28,47,48,49,50$.

It is important to discuss the limitations of this study as well as its strengths. The first potential limitation of this study is the cross-sectional nature of the analyses. Second, the information used in this study is based on the retrospective birth history of children and reported characteristics of mothers and households by the mother's of the children, which may cause underreporting in age. Third, only surviving women were interviewed, which may have lead to an underestimate of the neonatal mortality rate, because of the association of neonatal deaths with maternal deaths. This could also have lead to an underestimate of the effect of some of the associated factors, such as delivery complications ${ }^{6}$. Fourth, as a secondary data set, we could not include weight of child at the time of birth which is an important predictor in the study of neonatal mortality. Another limitation with household wealth indices derived from DHS is that those are based on current status data so that the variable might not capture the true level of household wealth during the infancy of children born several years before the survey. However, since these analyses are restricted to births within five years of the surveys, this biasness will not be substantial. Despite these limitations, the strength of the study is that it dealt with a large nationally representative sample size with stratified random sampling gathered by international standardized method, which are mostly used in public health research.

\section{Conclusion}

In summary, we found that twin or multiple births are more likely to be dying during the first four weeks of life as compared to singleton children. Maternal education, religion, maternal age and birth order are also important determinants of neonatal mortality in Bangladesh. This evidence suggests that improving maternal education may be key factor to improving child survival in Bangladesh. A well educated mother has a better chance of satisfying important factors that can improve infant survival: the quality of infant feeding, general care, household sanitation, and adequate use of preventive and curative health services. Adolescents should be discouraged to initiate childbearing at the teen ages not only for the reduction of neonatal mortality, also for their physical and psychological maturity that may bring overall wellbeing to mother and child health.

\section{Acknowledgements: None \\ Funding: Nil \\ Conflict of Interest: None}

Permission from IRB: Data used in this study have been taken from a nationally representative survey. The 
survey was conducted by a Bangladeshi government run institution. It followed all criteria and ethical issues prescribed by World Health Organization. This data set is widely used for public health research in home and abroad.

\section{References}

1. Malqvist M. Neonatal mortality: an invisible and marginalized trauma. Global Health Action 2011;4:5724.

2. Black RE, Cousens S, Johnson HL, Lawn JE, Rudan I, Bassani DG, Jha P, Cambell H, Walker CF, Cibulskis $\mathrm{R}$, Eisele T, Liu L, Mathers C. Global, regional, and national causes of child mortality in 2008: a systematic analysis. Lancet 2010;375:1969-87.

3. Lawn JE, Kerber K, Enweronu-Laryea C, Massee Bateman O. Newborn survival in low resource settings -are we delivering? BJOG 2009;116:49-59.

4. World Health Organization (WHO). The world health report 2005: make every mother and child count. Geneva, Switzerland, 2005.

5. Rajaratnam JK, Marcus JR, Flaxman AD, Wang $H$, Levin-Rector A, Dwyer L, Costa M, Lopez AD, Murray CJL. Neonatal, postneonatal, childhood, and under-5 mortality for 187 countries, 1970-2010: a systematic analysis of progress towards Millennium Development Goal 4. Lancet 2010, 375:1988-2008.

6. Titaley CR, Dibley MJ, Agho K, Roberts CL and Hall1 J. Determinants of neonatal mortality in Indonesia. BMC Public Health 2008;8:232.

7. Hill K, Choi Y. Neonatal mortality in the developing world. Dem Res 2006;14:429-52.

8. Moss W, Darmstadt GL, Marsh DR, Black RE, Santosham M. Research priorities for the reduction of perinatal and neonatal morbidity and mortality in developing country communities. J Perinatol 2002;22:484-95.

9. United Nations Children's Fund (UNICEF). Levels and trends in child mortality report 2010. New York: UNICEF, USA, 2010.

10. Rutstein SO. Factors associated with trends in infant and child mortality in developing countries during the 1990s. Bull World Health Organ 2000;78:1256-70.

11. Haines A, Cassels A. Can the millennium development goals be attained? BMJ 2004;329:39497.

12. Mitra SN, Ali MN, Islam S, Cross AR and Saha T. Bangladesh Demographic and Health Survey, 19931994. Calverton, Maryland: National Institute of Population Research and Training (NIPORT), Mitra and Associates, and Macro International Inc., 1994.
13. National Institute of Population Research and Training (NIPORT), Mitra and Associates, and Macro International. Bangladesh Demographic and Health Survey 2007. Dhaka, Bangladesh and Calverton, Maryland, USA: National Institute of Population Research and Training, Mitra and Associates, and Macro International, 2009.

14. Alam N, Haq MZ and Streatfield PK. Spatio-temporal patterns of under-five mortality in Matlab HDSS in rural Bangladesh. Global Health Action 2010;30:3.

15. Schoeps $D$, de Almeida MF, Alencar GP, França Jr. I, Novaes HMD, de Siqueira AAF, Campbell O and Rodrigues LC. Risk factors for early neonatal Mortality. Rev Saude Publica 2007;41:1-9.

16. Chowdhury ME, Akhter $\mathrm{HH}$, Chongsuvivatwong Vand Geater AF. Neonatal mortality in rural Bangladesh: an exploratory study. J Health Popul Nutr 2005;23:16-24.

17. Subramanian SV, Nandy S, Irving M, Gordon D, Lambert H, Davey SG. The mortality divide in India: the differential contributions of gender, caste, and standard of living across the life course. Am J Public Health 2006;96:818-25.

18. Abuqamar M, Coomans D and Louckx F. The impact of parental education on infant mortality in Gaza strip, Palestine. J Public Health Epidemiol 2011;3:2833.

19. Seedhom $A E$, Kamal NN. Some determinants of neonatal mortality in a rural area, El-Minia governorate, Egypt, 2008. Egyptian J Comm Med 2010;28:63-72.

20. Markovitz BP, Cook R, Flick LH, Leet TL. Socioeconomic factors and adolescent pregnancy outcomes: distinctions between neonatal and postneonatal deaths? BMC Public Health 2005;5:79.

21. Smeeton NC, Rona RJ, Dobson P, Cochrane R and Wolfe $C$. Assessing the determinants of stillbirths and early neonatal deaths using routinely collected data in an inner city area. BMC Medicine 2004;2:27.

22. Machado CJ, Hill K. Maternal, neonatal and community factors influencing neonatal mortality in Brazil. J Biosoc Sci 2005;37:193-208.

23. Zanini RR, de Moraes AB, Giugliani ERJ and Riboldi J. Contextual determinants of neonatal mortality using two analysis methods, Rio Grande do Sul, Brazil. Rev Saude Publica 2011;45:1-10.

24. Ahamad MG, Tasnima K, Khaled N, Bairagi SK and Deb UK. Infant mortality situation in Bangladesh in 2007: a district level analysis. MPRA Working paper No. 21102. Centre for Policy Dialogue (CPD), University of Muenchen, Germany, 2010. 
25. Mahmood MA. Determinants of neonatal and post-neonatal mortality in Pakistan. Pak Dev Rev 2002;41:723-44.

26. Mosley WH, Chen LC. An analytical framework for the study of child survival in developing countries. Pop Deve Rev 1984;10:25-45.

27. Jehan I, Harris $H$, Salat S, Zeb A, Mobeen N, Pasha O, McClure EM, Moore J, Wright LL and Goldenberg RL. Neonatal mortality, risk factors and causes: a prospective population-based cohort study in urban Pakistan. Bull World Health Organ 2009;87:130-38.

28. Alam N, Van Ginneken JK, Bosch AM. Infant mortality among twins and triplets in rural Bangladesh in 1975-2002. Trop Med Int Health 2007;12:1506-14.

29. Singh GK, Kogan MD. Persistent socioeconomic disparities in infant, neonatal, and postneonatal mortality rates in the United States, 1969-2001. Pediatrics 2005; 119:e928-e939.

30. Joshi R. Perinatal and neonatal mortality in rural Punjub. Working Paper No. 3. Achutha Menon Centre for Health Science Studies, Sree Chitra Tirunal Institute for Medical Sciences and Technology, Kerala, India, 2003.

31. Cleland JG, van Ginneken JK. Maternal education and child survival in developing countries: the Search for pathways of influence. Soc Sci Med 1988;27:1357-68.

32. Caldwell JC. Mass education as a determinant of mortality decline. In Selected Readings in the Cultural, Social and Behavioural Determinants of Health, ed. Caldwell and Santow. Canberra, Australia: Health Transition Center, The Australian National University, 1989.

33. Gupta DM. Death clustering, mothers' education and the determinants of child mortality in Punjab, India. Pop Stud 1990;44:489-505.

34. Kaunitz M, Spence C, Danilson T, Rochat R, Grimas D. Perinatal mortality in a religious group avoiding obstetric care. American J Obstet Gynecol 1984; 150:826-30.

35. Kamal SMM. Socio-economic determinants of age at first marriage of the ethnic tribal women in Bangladesh. Asian Pop Stud 2011;7:69-84.

36. Kamal SMM. Factors affecting utilization of skilled maternity care services among married adolescents in Bangladesh. Asian Pop Stud 2009;5:153-70.

37. Sharma B, Katz J, Mullany LC, Khatry SK, LeClerq SC, Shrestha SR, Darmstadt GL, Tielsch JM. Young maternal age and the risk of neonatal mortality in rural Nepal. PMC 2009;162:828-35.

38. Seoud MA, Nassar AH, Usta IM, Melhem Z, Kazma A, Khalil AM. Impact of advanced maternal age on pregnancy outcome. Am J Perinatol 2002;19:1-8.

39. Aldous MB, Edmonsom MB. Maternal age at first childbirth and risk of low birth weight and preterm delivery in Washington State. JAMA 1993;270:257477.

40. Ekwo EE, Moawad A. Maternal age and preterm births in a black population. Paediatr Perinat Epidemiol 2000;14:145-51.

41. Chan A, Keane RJ, Robinson JS. The contribution of maternal smoking to preterm birth, small for gestational age and low birth weight among Aboriginal and non-Aboriginal births in South Australia. Med J Aust 2001;174:389-93.

42. Mondal B. Risk factors for low birth weight in Nepali infants. Indian J Pediatr 2000;67:477-82.

43. Dutt D, Srinivasa DK. Impact of maternal and child health strategy on child survival in a rural community of pondicherry. Indian $J$ Pediatr 1997;34:785-92.

44. Wang PD, Lin RS. Perinatal mortality in Taiwan. Public Health 1999;113:27-33.

45. Hailemariam A, Tesfaye M. Determinants of infant and early childhood mortality in a small urban community of Ethiopia: a hazard model analysis. Ethiopian J Health Dev 1997;11:189-200.

46. Hobcraft JN, Mcdonald JW, Rutstein SO. Demographic determinants of infant and early child mortality: a comparative analysis. Pop Stud 1985;39:363-85.

47. Justesen A, Kunst A: Postneonatal and child mortality among twins in Southern and Eastern Africa. Int J Epidemiol 2000;29:678-83.

48. Ananth CV, Joseph KS, Demissie K, Vintzileos AM. Trends in twin preterm birth subtypes in the United States, 1989 through 2000: impact on perinatal mortality. Am J Obstet Gynecol 2005;193:1076-82.

49. Joseph KS, Marcoux S, Ohlsson A, Kramer MS, Allen AC, Liu S, Wu Wen S, Demissie K, Sauve R, Liston R. Preterm birth, stillbirth and infant mortality among triplet births in Canada, 1985-96. Paediatr Perinat Epidemiol 2002;16:141-48.

50. Uthman OA, Uthman MB and Yahaya I. A populationbased study of effect of multiple birth on infant mortality in Nigeria. BMC Pregnancy and Childbirth 2008;8:41.

\section{How to cite this article?}

Kamal SMM, Ashrafuzzaman M, Nasreen SA. Risk Factors of Neonatal Mortality in Bangladesh. J Nepal Paediatr Soc 2012;32(1):37-46. 